\title{
Fabrication and Characterization of CMOS-MEMS Thermoelectric Micro Generators
}

\author{
Pin-Hsu Kao ${ }^{1}$, Po-Jen Shih ${ }^{2}$, Ching-Liang Dai ${ }^{1}{ }^{*}$ and Mao-Chen Liu ${ }^{1}$
}

1 Department of Mechanical Engineering, National Chung Hsing University, Taichung, 402, Taiwan; E-Mails: d9461402@mail.nchu.edu.tw (P.-H.K.); d9361301@mail.nchu.edu.tw (M.-C.L.)

2 Department of Civil and Environmental Engineering, National University of Kaohsiung, Kaohsiung, 811, Taiwan; E-Mail: pjshih@ nuk.edu.tw

* Author to whom correspondence should be addressed; E-Mail: cldai@dragon.nchu.edu.tw; Tel.: +886-4-22840433; Fax: +886-4-22877170.

Received: 24 December 2009; in revised form: 28 January 2010 / Accepted: 1 February 2010 / Published: 9 February 2010

\begin{abstract}
This work presents a thermoelectric micro generator fabricated by the commercial $0.35 \mu \mathrm{m}$ complementary metal oxide semiconductor (CMOS) process and the post-CMOS process. The micro generator is composed of 24 thermocouples in series. Each thermocouple is constructed by p-type and n-type polysilicon strips. The output power of the generator depends on the temperature difference between the hot and cold parts in the thermocouples. In order to prevent heat-receiving in the cold part in the thermocouples, the cold part is covered with a silicon dioxide layer with low thermal conductivity to insulate the heat source. The hot part of the thermocouples is suspended and connected to an aluminum plate, to increases the heat-receiving area in the hot part. The generator requires a post-CMOS process to release the suspended structures. The post-CMOS process uses an anisotropic dry etching to remove the oxide sacrificial layer and an isotropic dry etching to etch the silicon substrate. Experimental results show that the micro generator has an output voltage of $67 \mu \mathrm{V}$ at the temperature difference of $1 \mathrm{~K}$.
\end{abstract}

Keywords: thermocouples; micro generators; CMOS-MEMS 


\section{Introduction}

With the development of electronic production processes, consumer electronic devices have become smaller and more portable. Power is an important issue for electronic devices. Micro generators can be applied in electronic devices providing additional power. The function of micro generators is not only to produce electric power but also to recycle and reuse waste energy. Many kinds of energy can be converted into electric power, for instance, wind power [1], thermal power [2], water power [3], chemical energy [4], and nuclear energy [5]. However, some energies cause environmental pollution and are not stable sources. Thermoelectric micro generators have a potential to convert heat into electric power. The heat is generated when electronic products are operating, so thermoelectric micro generators can recycle the heat as electric power and can reduce thermal spreading and alleviate global warming. Several micro devices have been manufactured using microelectromechanical system (MEMS) technology [6]. Many studies have employed MEMS technology to develop thermoelectric generators. For example, Huesgen et al. [7] used a combined surface and bulk micromachining process to fabricate thermoelectric generators with thermocouples on the silicon wafer. One thermocouple junction was connected by electroplated metal strips to the heat source and insulated to the heat sink by a cavity in the substrate. Wang et al. [8] proposed a thermoelectric micro generator based on n-type and p-type $\mathrm{Bi}_{2} \mathrm{Te}_{3}$ nanowire array thermoelectric materials. The nanowire arrays were produced using electrochemical deposition of $\mathrm{Bi}_{2} \mathrm{Te}_{3}$ on the nano-pores of an alumina template, and the Seebeck coefficient of p-type and n-type $\mathrm{Bi}_{2} \mathrm{Te}_{3}$ nanowire arrays was about 260 and $-188 \mu \mathrm{V} / \mathrm{K}$, respectively. Sato et al. [9] manufactured a thermoelectric generator using the thick-film formation processes with gold electroplating and deep reactive ion etching of silicon. The thermoelectric generator of gold and silicon produced voltages in accordance with the temperature difference at the thermocouples. $\mathrm{Qu}$ et al. [10] presented a flexible thermoelectric generator that's fabrication involved foil lithography, electroplating, embedding and wet chemical etching. The generator was composed of $\mathrm{Sb}-\mathrm{Bi}$ thermocouple strips embedded in a $50 \mu \mathrm{m}$ thick flexible epoxy film and was capable of generating a voltage of $0.25 \mathrm{~V}$ at a temperature difference of $30 \mathrm{~K}$. If the fabrication of thermoelectric generators is compatible with the commercial CMOS process, then the generators have a potential to combine with integrated circuits on a chip. The processes of the above studies [6-9] are not compatible with the CMOS process. In this study, we develop a thermoelectric generator that's fabrication is compatible with the CMOS process. Thermocouples, which are able to convert heat into voltage output, can be designed as a temperature sensor or a thermoelectric generator. The difference between both the devices is that the output of a thermoelectric generator focuses on the output power besides the output voltage. In this work, thermocouples are adopted to design the thermoelectric micro generator.

The use of the commercial CMOS process to manufacture MEMS devices is called CMOS-MEMS technique [11-13]. Micro devices fabricated by the CMOS-MEMS technique are usually a post-CMOS process to release the suspended structures [14] or to coat the functional films [15]. The advantages of CMOS-MEMS micro devices include compatibility with integrated circuits, low cost per unit area, and mass-production utilizing semiconductor foundries. In this work, we employ the CMOS-MEMS technique to fabricate a thermoelectric micro generator. The structure of the micro generator consists of 24 thermocouples in series and an aluminum plate, and the hot part of the thermocouples is connected 
to the aluminum plate that can conduct heat and increase the heat-receiving of the hot part. The cold part of the thermocouples is covered with a silicon dioxide layer for insulating the heat source. In order to increase the temperature difference at the thermocouples, the aluminum plate and the hot part of the thermocouples are designed as suspended structures. Thereby, the micro generator needs a post-CMOS process to release the suspended structures. The post-CMOS process includes an anisotropic dry etching to etch the silicon dioxide layer and an isotropic dry etching to remove the silicon substrate under the suspended structures. The experimental results depict that the output voltage of the micro generator is $67 \mu \mathrm{V}$ at the temperature difference of $1 \mathrm{~K}$.

\section{Design of the Generator}

Figure 1 illustrates a schematic of the thermoelectric micro generator. The generator consists of 24 thermocouples in series. The materials of the thermocouples are n-type and p-type polysilicons. Each thermocouple is constructed by two strips; one strip is p-type polysilicon and the other is n-type polysilicon. The dimensions of each thermocouple are $640 \mu \mathrm{m}$ long, $5 \mu \mathrm{m}$ wide and $0.3 \mu \mathrm{m}$ thick. The area of the generator is about $850 \times 850 \mu \mathrm{m}^{2}$.

Figure 1. Schematic of the thermoelectric micro generator.

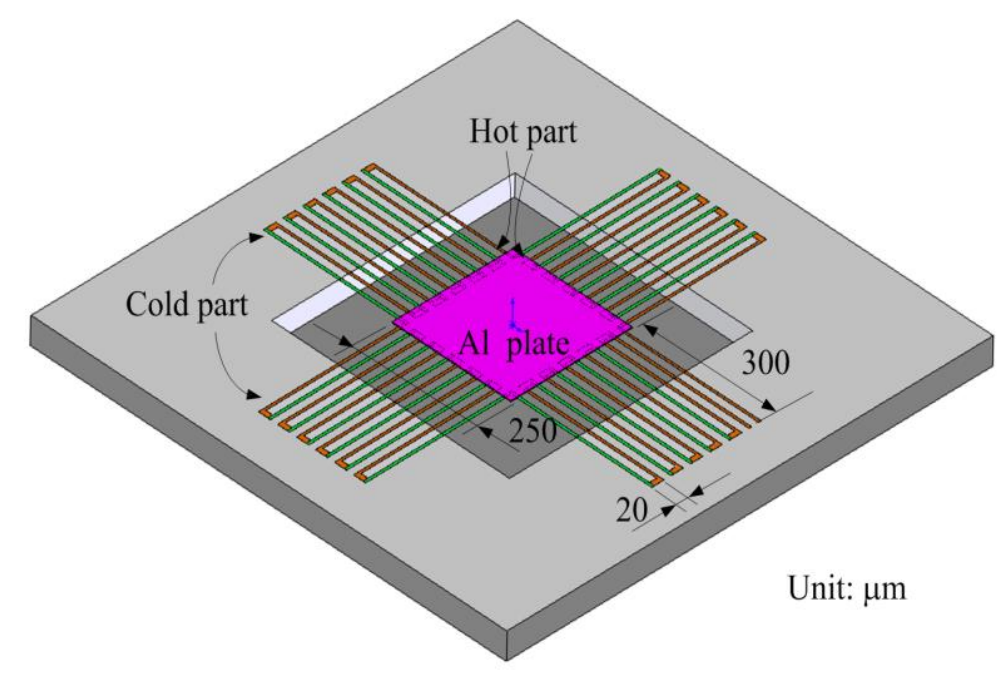

As shown in Figure 1, one junction of p-type and n-type polysilicon strips covered with silicon dioxide is the cold part of the thermocouples, and the other junction of p-type and n-type polysilicon strips to be suspended is the hot part of the thermocouples. In order to increase the temperature difference between the hot and cold parts, silicon dioxide with low thermal conductivity is utilized to cover the cold part. In addition to being suspended, the hot part is connected to an aluminum plate, which is used to conduct heat and increase the heat-receiving area. The finite element method (FEM) software, CoventorWare, is employed to simulate the temperature distribution of the micro generator. The model of the generator was established in accordance with Figure 1, and the Manhattan brick was used to mesh the model. The parabolic element was adopted. The thickness and thermal conductivity of the materials are summarized in Table 1. The initial temperature of $300 \mathrm{~K}$ was set, and the heat source of $301 \mathrm{~K}$ was applied to the aluminum plate of the generator. Figure 2 shows the simulated 
results of temperature distribution for the micro generator. The results showed that the suspended aluminum plate had a uniform temperature of $301 \mathrm{~K}$. Figure 3 illustrates the cross-sectional temperature distribution for half of the micro generator. The silicon dioxide layer over the cold part of the thermocouples successfully isolates the heat source.

Figure 2. Simulation of temperature distribution for the generator.

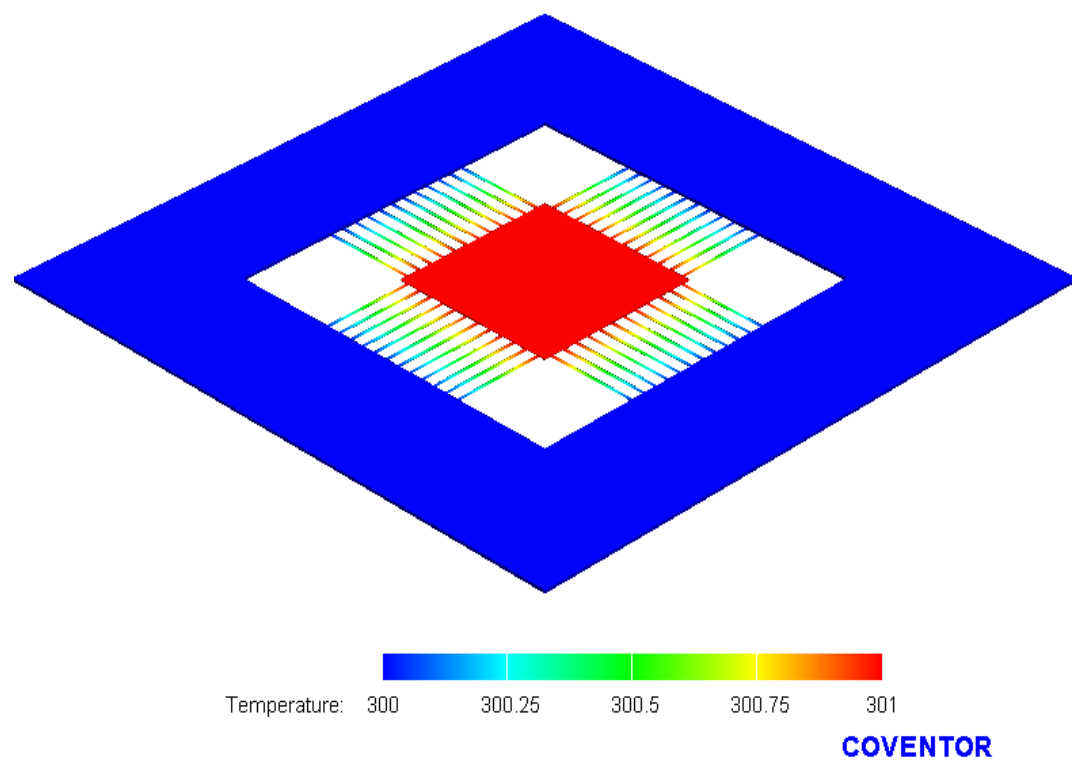

Figure 3. Cross-sectional view of temperature distribution for the generator.
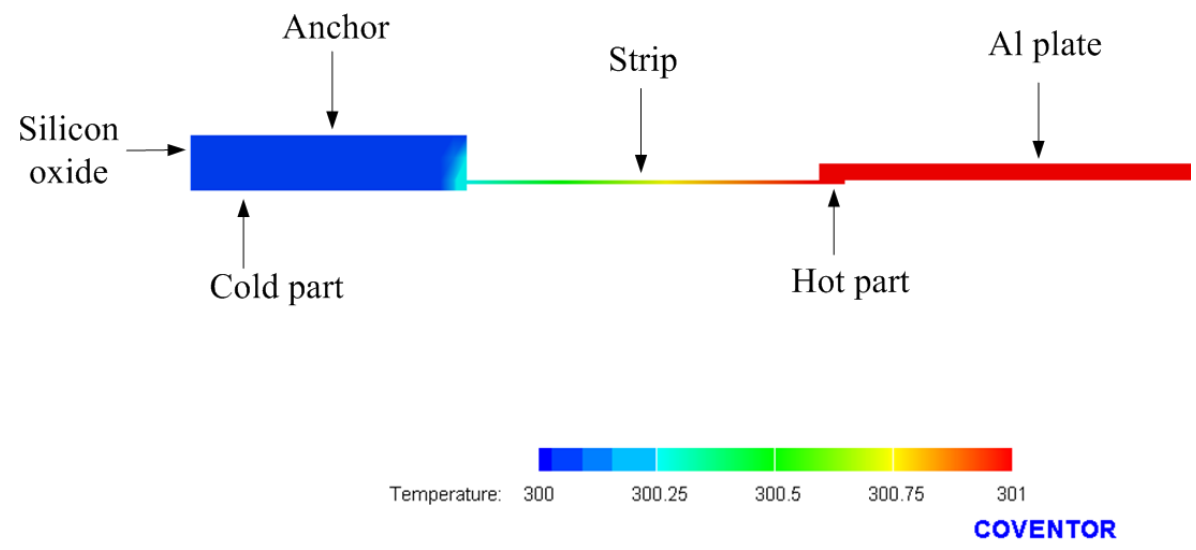

Table 1. Thickness and thermal conductivity of the materials.

\begin{tabular}{ccc}
\hline Material & Thickness $(\boldsymbol{\mu m})$ & Thermal conductivity $(\mathbf{p W} / \boldsymbol{\mu m}-\mathbf{K})$ \\
\hline $\mathrm{Al}$ & 0.6 & $2.36 \times 10^{8}$ \\
$\mathrm{SiO}_{2}$ & 5 & $1.42 \times 10^{6}$ \\
Polysilicon & 0.3 & $3.2 \times 10^{7}$ \\
\hline
\end{tabular}

The output voltage depends on the number of thermocouples. The relationship between the output voltage and the number of thermocouples is given by [16], 


$$
V_{\text {out }}=n\left(\alpha_{1}-\alpha_{2}\right)\left(T_{h}-T_{c}\right)
$$

where $V_{\text {out }}$ represents the output voltage generated by the thermoelectric effect; $n$ is the number of thermocouples connected in series; $\alpha_{1}$ and $\alpha_{2}$ are the Seebeck coefficients of p-type and n-type polysilicons, respectively; and $T_{h}$ and $T_{c}$ are the temperatures of the hot and cold parts, respectively. According to Equation (1), we know that the output voltage relies on the number of thermocouples, the Seebeck coefficient of materials and the temperature difference. The output voltage, $V_{\text {out }}$, is proportional to the number of thermocouples, $n$, and the relative Seebeck coefficient, $\alpha_{1}-\alpha_{2}$. In this work, the n-type and p-type polysilicons are adopted as the materials of the thermocouples owing to their large relative Seebeck coefficient. In this design, the number of thermocouples is 24 , and the relative Seebeck coefficient of the n-type and p-type polysilicons is about $0.004 \mathrm{mV} / \mathrm{K}$. The output voltage of the generator can be evaluated by substituting the values $n=24$ and $\alpha_{1}-\alpha_{2}=0.004 \mathrm{mV} / \mathrm{K}$ into Equation (1), and the results are plotted in Figure 4. The calculated results show that the output voltage of the generator was $96 \mu \mathrm{V}$ at the temperature difference of $1 \mathrm{~K}$.

Figure 4. Simulated results of the output voltage for the generator.

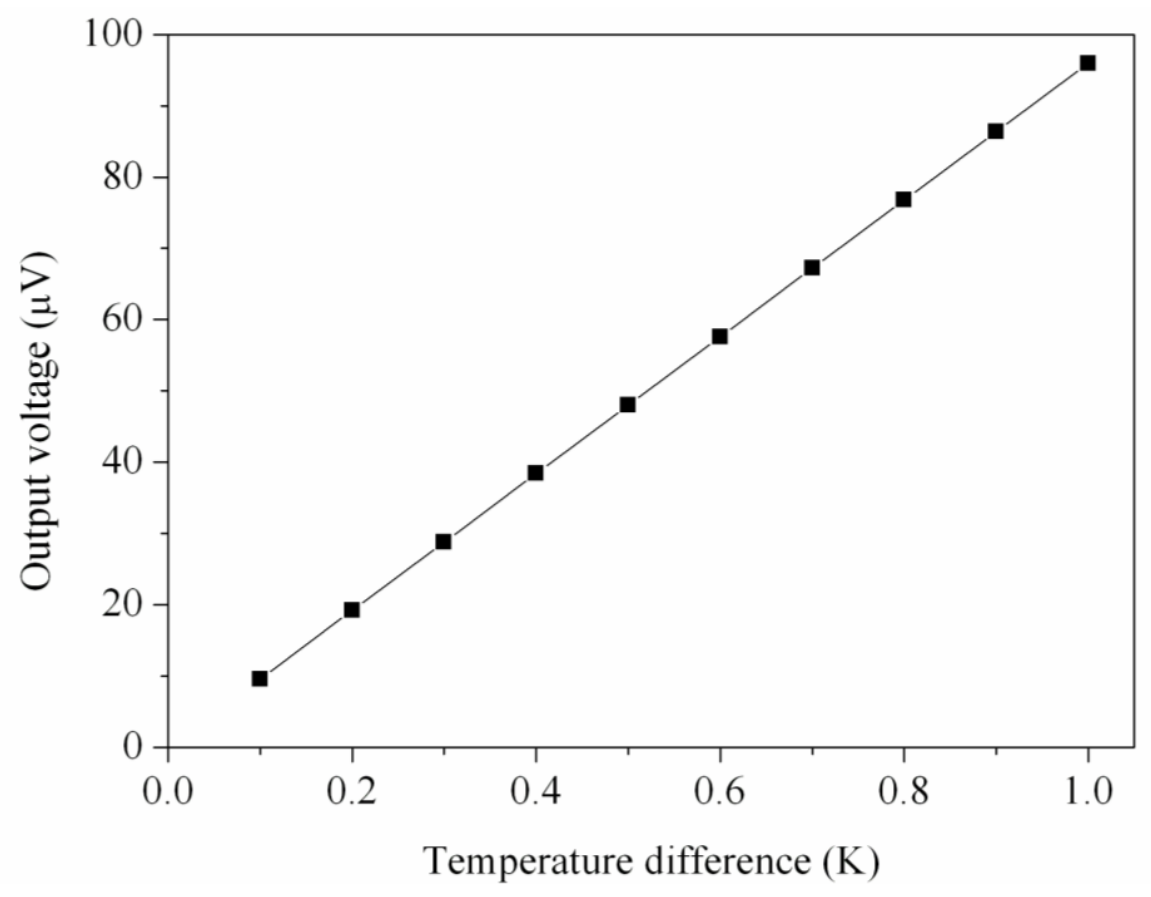

If the external load, $R$, that is the same the inertial load is connected, the maximum output power of the generator can be obtained by [9],

$$
P_{\max }=\frac{V_{o u t}^{2}}{4 R}
$$

Furthermore, substituting Equation (1) into Equation (2), the maximum output power of the generator can be written as,

$$
P_{\max }=\frac{n^{2}\left(\alpha_{1}-\alpha_{2}\right)^{2}\left(T_{h}-T_{c}\right)^{2}}{4 R}
$$


In this design, the parameters are $n=24, \alpha_{1}-\alpha_{2}=0.004 \mathrm{mV} / \mathrm{K}$ and $R=2.45 \mathrm{k} \Omega$. Substituting the values into Equation (3), the maximum output power of the generator can be yielded and the results are plotted in Figure 5. The results show that the output power of the generator was about $0.94 \mathrm{pW}$ at the temperature difference of $1 \mathrm{~K}$.

Figure 5. Simulated results of the output power for the generator.

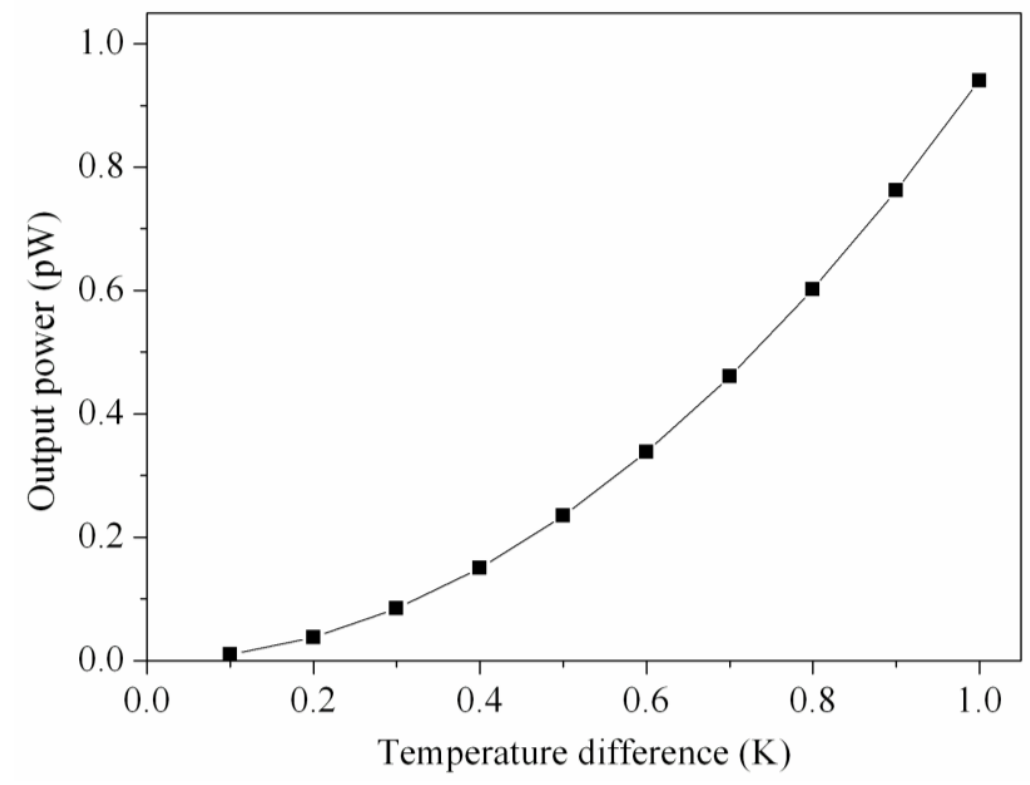

\section{Fabrication of the Generator}

The thermoelectric micro generator is manufactured using the commercial $0.35 \mu \mathrm{m}$ CMOS process of Taiwan Semiconductor Manufacturing Company (TSMC). Figure 6 illustrates the process flow of the micro generator. Figure 6a shows the cross-section of the micro generator after completion of the CMOS process. The thickness of the sacrificial oxide, field oxide, polysilicon, aluminum, and passivation layers is about $6.4 \mu \mathrm{m}, 0.28 \mu \mathrm{m}, 0.3 \mu \mathrm{m}, 0.6 \mu \mathrm{m}$ and $1 \mu \mathrm{m}$, respectively. In order to insulate the heat sink of the hot part and the aluminum plate, these structures have to be suspended, so the generator needs a post-CMOS process to etch the sacrificial layers, and to release the suspended structures. The post-CMOS process contains three steps. First, a photoresist is coated on the surface of the generator using a spinner, and it is patterned by a lithograph. Then, the oxide sacrificial layer is etched using a reactive ion etch (RIE) with $\mathrm{CHF}_{3} / \mathrm{O}_{2}$, which is an anisotropic dry etching for the oxide layer. Figure $6 \mathrm{~b}$ displays the oxide sacrificial layer in the generator to be removed after the anisotropic dry etching. Next, the silicon substrate is etched using a RIE with $\mathrm{XeF}_{2}$, which is an isotopic etching for the silicon substrate, so that the suspended structures are released owing to undercut. Figure $6 \mathrm{c}$ shows the suspended structures released after the isotropic dry etching. Finally, the photoresist is striped by acetone. Figure 7 presents a scanning electron microscope (SEM) image of the micro generator after the post-CMOS process. 
Figure 6. Process flow of the generator (a) after completion of the CMOS process; (b) etching the oxide sacrificial layer; (c) etching the silicon substrate.
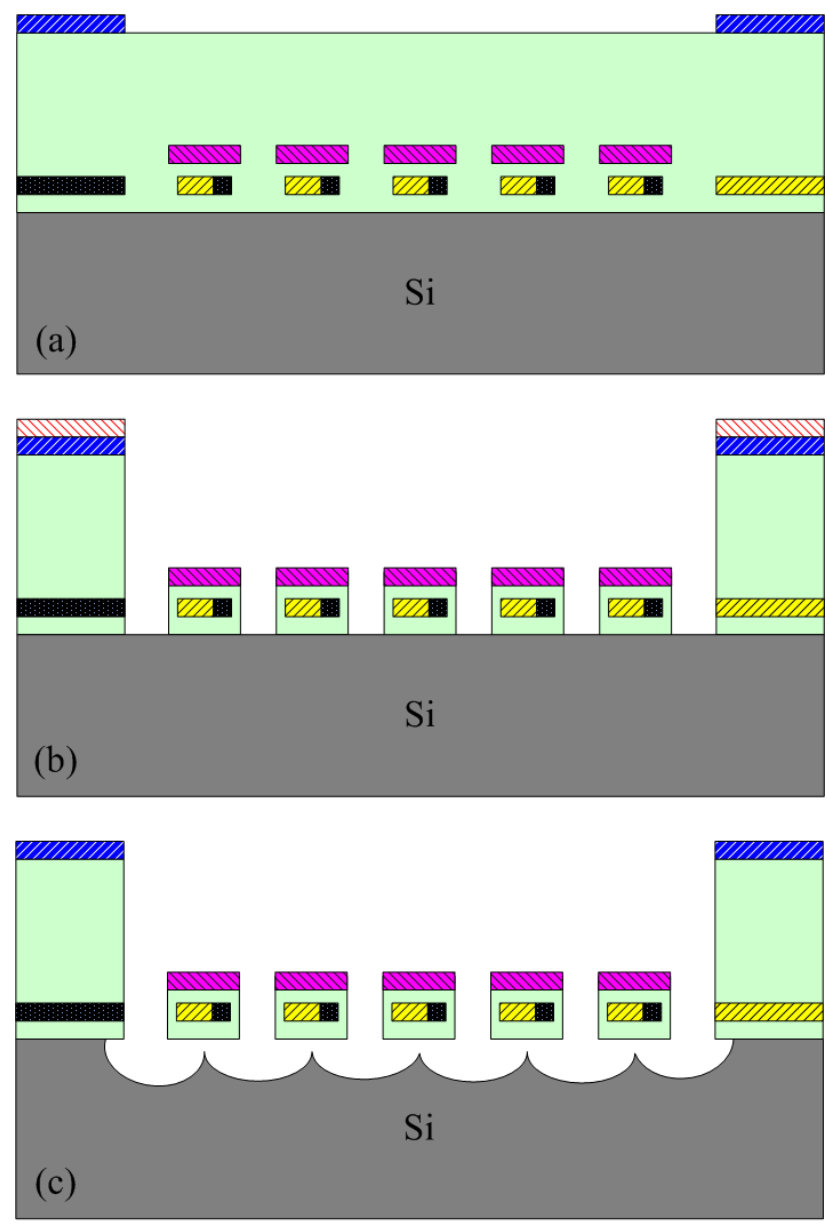

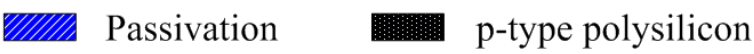
Silicon dioxide VIIIA n-type polysilicon Photoresist Metal (Al)

Figure 7. SEM image of the generator after the post-CMOS process.

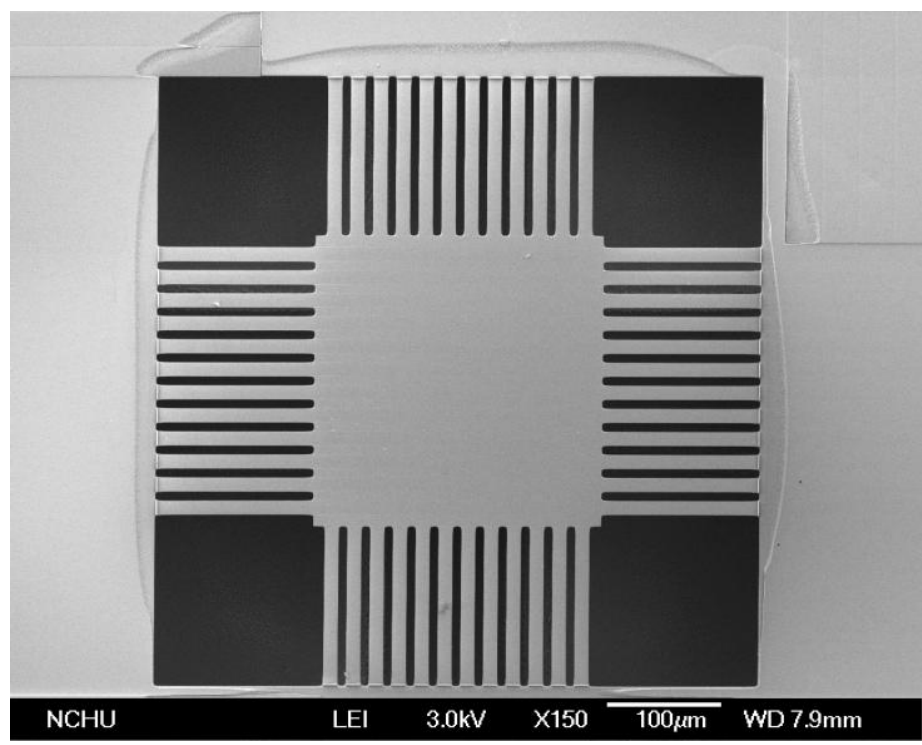




\section{Results and Discussion}

A heat source, an infrared temperature detector, and a multifunction electrical meter were utilized to measure the characteristics of the micro generator. The heat source provided a heat flux to the micro generator, and the infrared temperature detector was used to measure the temperature difference between the hot and cold parts of the thermocouples. The multifunction electrical meter was employed to measure the output voltage of the generator. Figure 8 depicts the measured results of the output voltage for the micro generator. The measured results show that the generator had an output voltage of $41 \mu \mathrm{V}$ at the temperature difference of $0.6 \mathrm{~K}$, and the output voltage was $67 \mu \mathrm{V}$ at the temperature difference of $1 \mathrm{~K}$. The output voltage per area of the generator was about $0.093 \mathrm{mV} \mathrm{mm} \mathrm{K}^{-1}$. Compared with the simulated results in Figure 4, where the simulated output voltage was $96 \mu \mathrm{V}$ at the temperature difference of $1 \mathrm{~K}$, the percentage of error is about $30 \%$. The cause of the error was either that the Seebeck coefficient of the materials in the thermocouples was changed by variations in the fabrication process or that the infrared temperature detector was not precise enough.

Figure 8. Output voltage of the generator.

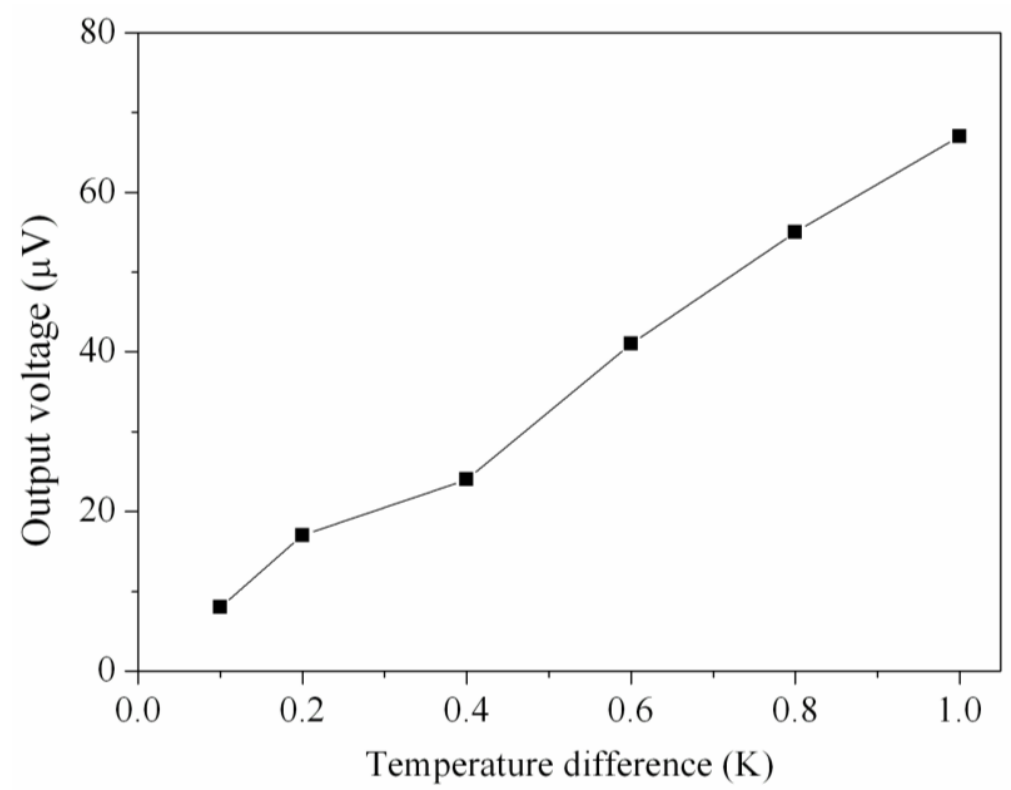

In addition, the resistance of the micro generator was detected. The heat source supplied a heat flux to the micro generator, and the resistance of the generator was measured by the multifunction electrical meter. Figure 9 shows the change of resistance for the generator with the temperature. The experimental results show that the resistance of the generator varied from 2.45 to $2.59 \mathrm{k} \Omega$ as the temperature changed from 300 to $370 \mathrm{~K}$. The resistance of the generator was proportional to the temperature, and it recovered to the initial state after the temperature fell, which the paths in Figure 9 were almost the same. 
Figure 9. Resistance of the generator.

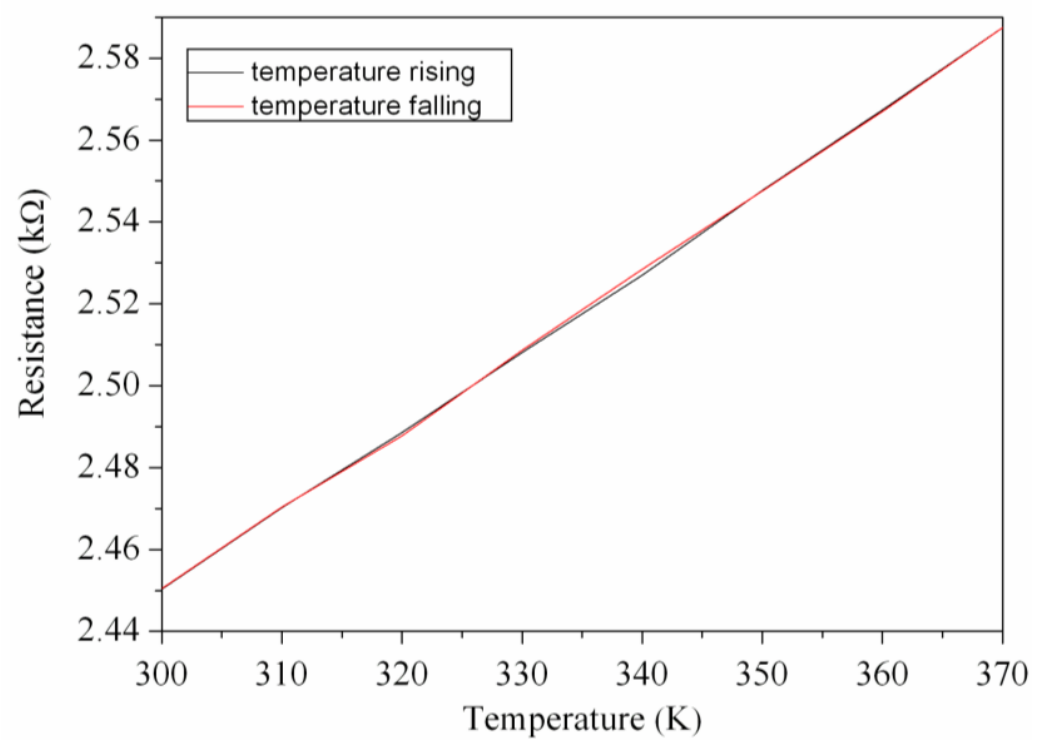

According to Equation (2), the output power of the generator relies on its output voltage and resistance. The measured output voltage in Figure 9 and the resistance $R=2.45 \mathrm{k} \Omega$ were substituted into Equation (2), the maximum output power of the generator was obtained, and the results were shown in Figure 10. The results revealed that the generator had an output power of $0.16 \mathrm{pW}$ as the temperature difference of $0.6 \mathrm{~K}$, and the output power of the generator increased to $0.46 \mathrm{pW}$ as the temperature difference changed to $1 \mathrm{~K}$. The power factor [7] of the generator was $6.4 \times 10^{-7} \mu \mathrm{W} \mathrm{mm} \mathrm{K}^{-2}$. A comparison to the simulated results in Figure 5, the simulated output power was $0.94 \mathrm{pW}$ at the temperature difference of $1 \mathrm{~K}$, so the output power had an error of $0.48 \mathrm{pW}$ at the temperature difference of $1 \mathrm{~K}$. Because the measured output voltage had an error existence, the output power in Figure 10 was evaluated by the measured output voltage, leading to the error in the output power.

Figure 10. Output power of the generator.

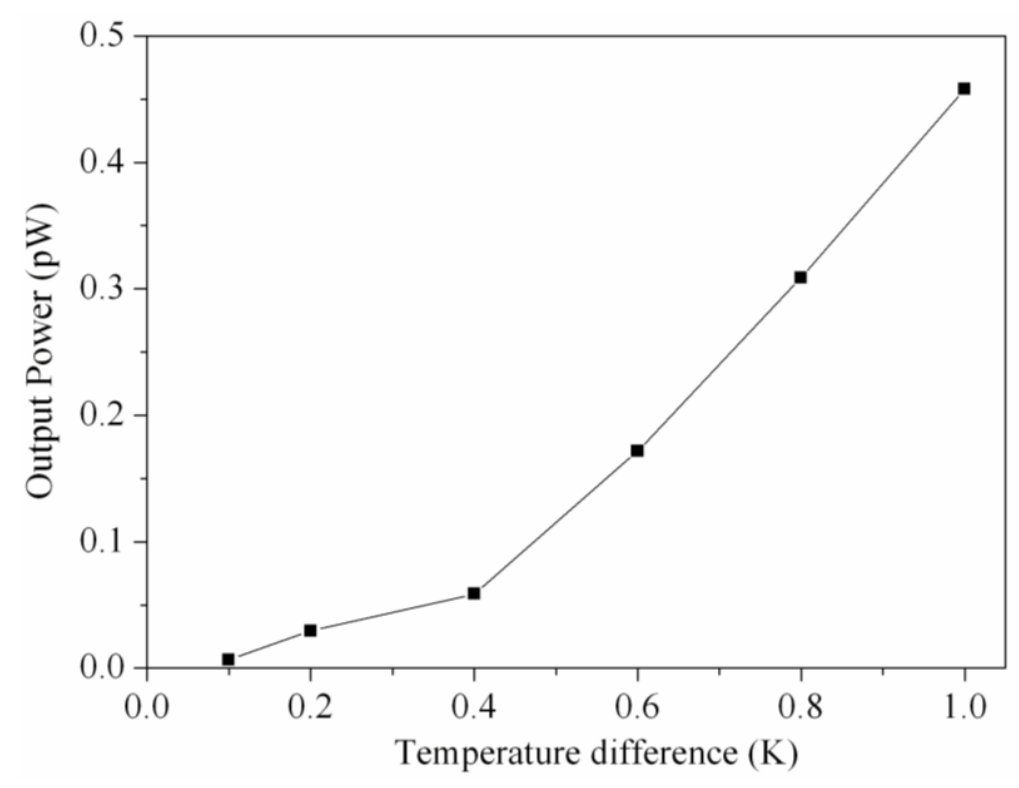


Huesgen et al. [7] presented a thermoelectric micro generator with thermocouples made of $\mathrm{Al}$ and $\mathrm{n}$-poly-Si, and it had an output voltage per area of $7.46 \mathrm{mV} \mathrm{mm} \mathrm{K}^{-1}$ and a power factor of $1.612 \times 10^{-4} \mu \mathrm{W} \mathrm{mm}{ }^{-2} \mathrm{~K}^{-2}$. Strasser et al. [16] proposed a poly-Si thermoelectric micro generator, which had an output voltage per area of $22 \mathrm{mV} \mathrm{mm}^{-2} \mathrm{~K}^{-1}$ and a power factor of $4.26 \times 10^{-4} \mu \mathrm{W} \mathrm{mm} \mathrm{K}^{-2}$. In this work, the generator had an output voltage per area of $0.093 \mathrm{mV} \mathrm{mm}{ }^{-2} \mathrm{~K}^{-1}$ and a power factor of $6.4 \times 10^{-7} \mu \mathrm{W} \mathrm{mm}{ }^{-2} \mathrm{~K}^{-2}$. In comparison to the literature, the output voltage and power factor of this work were lower than that of Huesgen et al. [7] and Strasser et al. [16].

\section{Conclusion}

The thermoelectric micro generator has been implemented using the CMOS-MEMS technique. The micro generator contained 24 thermocouples in series, and the materials of the thermocouples were p-type and n-type polysilicons. The output power of the generator was proportional to the square of the temperature difference between the hot and cold parts in the thermocouples. In order to increase the temperature difference of the thermocouples, the cold part was covered with a silicon dioxide layer to insulate the heat source, and the hot part was suspended and connected to an aluminum plate for increasing heat-receiving. The micro generator needed a post-CMOS process to release the aluminum plate and the hot part of the thermocouples. The post-CMOS process employed an anisotropic dry etching with $\mathrm{RIE} \mathrm{CHF}_{3} / \mathrm{O}_{2}$ to remove the oxide sacrificial layer, and then an isotropic dry etching with $\mathrm{RIE} \mathrm{XeF}_{2}$ was adopted to etch the silicon substrate to release the suspended structures. The advantage of the post-CMOS process was that it was compatible with the commercial CMOS process. Experimental results revealed that the output voltage of the micro generator was about $67 \mu \mathrm{V}$ at the temperature difference of $1 \mathrm{~K}$.

\section{Acknowledgements}

The authors would like to thank National Center for High-performance Computing (NCHC) for chip simulation, National Chip Implementation Center (CIC) for chip fabrication for financial support, and the National Science Council of the Republic of China for financially supporting this research under Contract No NSC 98-2221-E-005-070.

\section{References}

1. Thakur, D.; Mithulananthan, N. Influence of constant speed wind turbine generator on power system oscillation. Electr. Power Compon. Syst. 2009, 37, 478-494,

2. Sodano, H.A.; Simmers, G.E.; Dereux, R.; Inman, D.J. Recharging batteries using energy harvested from thermal gradients. J. Intell. Mat. Syst. Struct. 2007, 18, 3-10.

3. Saket, R.K. Design, development and reliability evaluation of micro hydro power generation system based on municipal waste water. IEEE Elect. Power Energ. Conf. Energ. Innovat. 2008, doi: 10.1109/EPC.2008.4763355. 
4. Lokhtin, I.P.; Malinina, L.V.; Petrushanko, S.V.; Snigirev, A.M.; Arsene, I.; Tywoniuk, K. Heavy ion event generator HYDJET (HYDrodynamics plus JETs). Comput. Phys. Commun. 2009, 180, 779-799.

5. Nisan, S.; Benzarti, N. A comprehensive economic evaluation of integrated desalination systems using fossil fuelled and nuclear energies and including their environmental costs. Desalination 2008, 229, 125-146.

6. Senturia, S.M. Microsystem Design; Kluwer Academic: Boston, MA, USA, 2001.

7. Huesgen, T.; Woias, P.; Kockmann, N. Design and fabrication of MEMS thermoelectric generators with high temperature efficiency. Sens. Actuators, A 2008, 145-146, 423-429.

8. Wang, W.; Jia, F.; Huang, Q.; Zhang, J. A new type of low power thermoelectric micro-generator fabricated by nanowire array thermoelectric material. Microelectron. Eng. 2005, 77, 223-229.

9. Sato, N.; Kuwabara, K.; Ono, K.; Sakata, T.; Morimura, H ; Terada, J.; Kudou, K.; Kamei, T.; Yano, M.; Machida, K.; Ishii, H. Monolithic integration fabrication process of thermoelectric and vibrational devices for microelectromechanical system power generator. Jpn. J. Appl. Phys. 2007, 46, 6062-6067.

10. Qu, W.; Plötner, M.; Fischer, W.J. Microfabrication of thermoelectric generators on flexible foil substrates as a power source for autonomous Microsystems. J. Micromech. Microengineer. 2001, $11,146-152$.

11. Baltes, H.; Brand, O. CMOS-based microsensors and packaging. Sens. Actuator. A 2001, 92, 1-9.

12. Kao, P.H.; Dai, C.L.; Hsu, C.C.; Lee, C.Y. Fabrication and characterization of a tunable in-plane resonator with low driving voltage. Sensors 2009, 9, 2062-2075.

13. Dai, C.L.; Chen, Y.L. Modeling and manufacturing of micromechanical RF switch with inductors. Sensors 2007, 7, 2660-2670.

14. Liu, M.C.; Dai, C.L.; Chan, C.H.; Wu C.C. Manufacture of a polyaniline nanofiber ammonia sensor integrated with a readout circuit using the CMOS-MEMS technique. Sensors 2009, 9 , 869-880.

15. Dai, C.L.; Lu, P.W.; Wu, C.C.; Chang, C. Fabrication of wireless micro pressure sensor using the CMOS process. Sensors 2009, 9, 8748-8760.

16. Strasser, M.; Aigner, R.; Lauterbach, C.; Sturm, T.F.; Franosch, M.; Wachutka, G.K.M. Micromachined CMOS thermoelectric generators as on-chip power supply. Sen. Actuator. A 2004, $114,362-370$.

(C) 2010 by the authors; licensee Molecular Diversity Preservation International, Basel, Switzerland. This article is an open-access article distributed under the terms and conditions of the Creative Commons Attribution license (http://creativecommons.org/licenses/by/3.0/). 